\title{
Sala de Recursos Multifuncional para alunos com deficiência intelectual: uma análise da proposta do Ministério da Educação
}

\author{
Eliane Brunetto Pertile* \\ Elisabeth Rossetto**
}

\section{Resumo}

O artigo expốe o resultado de uma pesquisa documental e bibliográfica que teve como objetivo investigar a proposta do Ministério da Educação (MEC) para a realizaçáo do trabalho docente com alunos com deficiência intelectual na Sala de Recursos Multifuncional (SRM). Para tanto, priorizou-se publicaçóes divulgadas pelo MEC que orientam a ação desses professores. À luz da Teoria Histórico-Cultural, analisa-se a concepçáo de desenvolvimento humano, de aprendizagem e de mediação docente (ensino) subjacente às orientaçôes anunciadas. Destaca-se ainda a importância atribuída (ou não) aos conteúdos escolares. Ao final dessa pesquisa, pode-se dizer que as orientaçôes propostas pelo MEC defendem uma perspectiva de educação que confere demasiada importância à espontaneidade. Assim, tem características antagônicas aos pressupostos da Teoria Histórico-Cultural. Constata-se que a preparação direcionada aos professores se encontra imbuída de características que denotam ênfase em procedimentos técnicos e na disponibilizaçáo do uso de recursos. Dessa forma, entende-se que a organização de uma ação educacional que impulsione o desenvolvimento intelectual dos alunos exige uma contra proposta que valorize a mediação docente e a apropriação dos conteúdos.

Palavras-chave: Sala de Recursos Multifuncional. Aluno com Deficiência Intelectual. Formação Docente.

\footnotetext{
* Mestre em Educação pela Universidade Estadual do Oeste do Paraná (UNIOESTE). Doutoranda em Educação pela Universidade Estadual de Maringá (UEM). Professora da Rede Estadual de Educação do Paraná.

** Doutora em Educaçấo pela Universidade Federal do Rio Grande do Sul (UFRGS). Professora do Centro de Educação, Comunicação e Artes e do Programa de Pós-Graduação em Educação da Universidade Estadual do Oeste do Paraná (UNIOESTE).
} 


\section{Introdução}

Apresentamos neste artigo, resultados de uma pesquisa documental e bibliográfica em nível de Mestrado (PERTILE, 2013), a qual elegeu como objeto de estudo, documentos veiculados pelo Ministério da Educação (MEC) para suporte aos processos escolares no que diz respeito ao trabalho pedagógico do professor da Sala de Recursos Multifuncional (SRM) com alunos com deficiência intelectual.

Trata-se, portanto, de um trabalho de análise cujo objetivo consistiu em compreender a proposta divulgada pelo MEC, bem como buscou identificar quais são as atividades docentes a serem desenvolvidas com alunos com deficiência intelectual, propostas pelos documentos orientadores, reconhecendo suas filiaçôes teóricas. Para alcançar o objetivo proposto, foi imprescindível conhecer a proposta de trabalho educacional apresentada pelo MEC, suas possibilidades e seus limites. Com esse intuito, dedicamo-nos à análise dos fundamentos teóricos subjacentes à linguagem que compóe as orientaçóes para o trabalho do professor.

Neste estudo, detemo-nos na área intelectual, por entendermos que essa delimitação nos permite aprofundar a discussão. Além disso, tal área apresenta grandes desafios às escolas, tendo em vista o compromisso educacional com a socialização dos conhecimentos científicos frente às necessidades diferenciadas que estes alunos apresentam para tal apropriação.

Nosso respaldo para a compreensão das pessoas com deficiência intelectual se encontra nos pressupostos da Teoria Histórico-Cultural, que entende o sujeito para além das definiçôes biológicas, vendo-o como determinado pela influência dos fatores sociais. Assim, essa concepção não se centra meramente na mensuração quantitativa e nos aspectos orgânicos, mas na valoração dos aspectos qualitativos, das mediaçôes e da cultura, constituintes das capacidades psíquicas e indispensáveis para a superação dos limites postos pela deficiência (VIGOTSKI, 1983).

Entretanto, não nos detivemos, neste momento, no debate de forma pormenorizada acerca dos fatores utilizados para a caracterizaçáo da deficiência intelectual, tendo em vista que, embora de grande relevância, essa questão nos remeteria a um percurso específico de discussão, com questôes bastante controversas como a avaliação, o uso dos testes psicométricos, entre outros, desviando-nos do estudo proposto.

Tomamos como referência para a definição do público, as disposiçóes estabelecidas a partir da legislação educacional da área da educação especial em vigência, pois, de acordo com as normativas que sucedem a Política Nacional de Educação Especial na Perspectiva da Educação Inclusiva de 2008, no espaço das SRM 
deve ser atendido todo o público-alvo da educação especial, sendo "alunos com deficiência, transtornos globais de desenvolvimento e altas habilidades/superdotação" (BRASIL, 2008, p. 7) matriculados na rede regular de ensino.

A Política Nacional de Educação Especial na Perspectiva da Educação Inclusiva (BRASIL, 2008) enfatiza a frequência de todos os alunos nas classes comuns das escolas regulares e apresenta contornos mais precisos ao Atendimento Educacional Especializado (AEE) em relação às normativas propostas anteriormente. A Resolução no 4, de outubro de 2009, prevê a matrícula dos alunos que constituem público-alvo da educação especial "nas classes comuns do ensino regular e no AEE ofertado nas Salas de Recursos Multifuncionais ou centros de Atendimento Educacional Especializado" (BRASIL, 2009). Nos documentos sequentes, a SRM destaca-se enquanto espaço prioritário para realização do AEE e pela possibilidade de organização de práticas pedagógicas diferenciadas que contemplem as necessidades específicas dos alunos.

Essas novas proposiçóes legais indicam a importância de formaçáo para os docentes como forma de atualizá-los para direcionarem as açôes do AEE, bem como estabelecem a relevância da SRM como apoio prioritário para a efetivação do processo de inclusão.

Assim, contemplamos, na investigação documental, publicaçóes que repercutem na formação do professor para o trabalho no AEE da SRM localizadas no portal online do $\mathrm{MEC}^{1}$. Além de disponíveis no site do MEC, esses materiais foram publicados, nos anos de $2007^{2}$ e $2010^{3}$, e distribuídos nacionalmente por meio desse órgão, o que os torna representativos das orientaçóes direcionadas aos docentes, dada a abrangência que obtiveram.

Fizemos um recorte temático nos fascículos e módulos que compóe o referido material, tendo em vista a área da deficiência intelectual. Assim, nos detemos nos seguintes documentos: Atendimento Educacional Especializado: aspectos legais e orientaçóes pedagógicas (BRASIL, 2007c) - embora este não seja específico para a área intelectual, também a contempla e apresenta delineamentos que incidem sobre todo o trabalho do AEE; Atendimento Educacional Especializado: Deficiência Mental (BRASIL, 2007); e Atendimento Educacional para alunos com Deficiência Intelectual (BRASIL, 2010).

É relevante e necessário o exercício de análise desses materiais, uma vez que acompanharam a formação docente na modalidade a distância proporcionada pelo MEC e foram propostos para responder as dúvidas dos professores sobre o crescente processo de inclusão de alunos com deficiência. Esses documentos de orientação ao trabalho do professor do AEE foram massivamente divulgados e formam, facilmente, um consenso acerca dos princípios a serem considerados e do trabalho a ser realizado na SRM. 
Portanto, consideramos que ao serem veiculados pelo MEC esses materiais são representativos dos direcionamentos que vem sendo dados às discussóes sobre o $\mathrm{AEE}$ em nível nacional. Além disso, assumem status de referência entre as proposiçóes que vão incidir sobre a formação dos professores das escolas públicas neste momento. Sendo assim, possuem caráter formativo, de cunho pedagógico, abordam o trabalho do AEE nas SRM e orientam acerca da ação educacional, especificando-a em cada área do público-alvo da educaçáo especial.

No plano metodológico, priorizamos a análise dos conceitos presentes no discurso divulgado pelas publicaçôes do governo federal. Compartilhamos a opinião de que "os sentidos não são dados nos documentos, são produzidos; estão aquém e além das palavras que os compóem" (SHIROMA; CAMPOS; GARCIA, 2005, p. 1). Assim, eles só podem ser entendidos tendo como parâmetro o contexto de sua produçâo e o próprio contexto de produção da vida nesta sociedade. Nesse sentido, empreendemos nossos esforços para considerar a totalidade das relaçóes sociais que determinam a vida dos homens e, consequentemente, os aspectos educacionais; buscamos, ainda, trazer à tona as contradiçóes que marcam as orientaçóes encaminhadas para o direcionamento dos processos escolares.

O estudo bibliográfico, por sua vez, tem como base teóricos que possibilitam o aprofundamento da Teoria Histórico-Cultural. Selecionamos textos de Lev Semenovich Vigotski $(1983,1997)$ e pesquisadores atuais que buscam interpretar a obra vigotskiana de forma articulada com as discussōes contemporâneas. Esses autores subsidiaram as discussôes, uma vez que, suas produçóes fornecem elementos para debater os materiais em análise.

\section{Formação para os professores da SRM na área da deficiência intelectual}

Procuramos nos materiais veiculados para formaçáo docente qual a natureza das atividades que o professor deve desenvolver na SRM com alunos da área intelectual. Assim, propomo-nos a compreender qual é a concepção de desenvolvimento humano, de aprendizagem e de mediação docente (ensino) subjacente às orientaçôes anunciadas para constituição de uma especificidade do AEE na SRM. Tais categorias orientaram o estudo do material e a análise propriamente dita e foram selecionadas devido à relevância que assumem no trabalho docente, podendo direcioná-lo de diferentes formas e para fins distintos e, principalmente, porque podem denotar a filiação teórica das orientaçóes divulgadas. Além disso, a Teoria Histórico-Cultural nos fornece elementos para a análise com base nas categorias mencionadas. 
Dentre os materiais divulgados, o módulo Aspectos Legais e Orientaçôes Pedagógicas (BRASIL, 2007c) aborda questóes jurídicas e discute os critérios da discriminação positiva na garantia de condições diferenciadas para os alunos com deficiência. Nessa perspectiva, o AEE é proposto como um atendimento que discrimina positivamente, pois acresce condiçôes distintas, mas não exclui outros direitos como o de frequência nos "estabelecimentos oficiais de ensino", se estes "não forem separados por grupos de pessoas" (BRASIL, 2007c, p. 16). O documento discute a inclusão escolar dos alunos com deficiência mental ${ }^{4}$ e alerta para os desafios que ela impóe para as escolas comuns. Além disso, questiona a eficiência das práticas escolares convencionais e o trabalho com o saber formal. Como proposiçáo, traz que: "Todos os alunos devem ser avaliados pelos progressos que alcançam nas diferentes áreas do conhecimento e a partir de seus talentos e potencialidades, habilidades naturais e construção de todo tipo de saber escolar" (BRASIL, 2007c, p. 42).

O material apresenta o perfil de escola desejado para, supostamente, atender com sucesso a todos os alunos. No modelo defendido, os conteúdos escolares sáo colocados em plano secundário, conforme vemos a seguir: "[...] o que se persegue, especialmente em fase de Ensino Fundamental, é a formação humana e a preparação emocional do aluno para prosseguir nos estudos. Não se descuida do conteúdo curricular, mas este deixa de ser o eixo central da escola [...]" (BRASIL, 2007c, p. 18, grifo nosso).

O capítulo "Orientaçôes pedagógicas" (BRASIL, 2007c), que pertence ao mesmo módulo, propóe que as escolas organizem mudanças de base e aprimorem suas práticas, a fim de atender as diferenças por meio de novas alternativas pedagógicas, que favoreçam a todos os alunos. Mas, ao discutir os aspectos relacionados ao ensino regular, apresenta críticas em relação às propostas curriculares questionando a valorização atribuída ao saber sistematizado e a socialização do conhecimento. É direcionada a importância para a relaçáo que o aluno tem com o saber, muito mais intensamente do que para a sua apropriaçáo. Tal aspecto leva-nos a supor uma desvalorização do conhecimento como representação e possibilidade de desenvolvimento humano, conforme vemos na seguinte afirmação:

As propostas curriculares devem reconhecer e valorizar os alunos em suas peculiaridades étnicas, de gênero, cultura; precisam partir de suas realidades de vida, de suas experiências, de seus saberes, fazeres e são tramadas em redes de conhecimento que superam a tão decantada sistematizaçâo do saber. (BRASIL, 2007c, p. 48, grifo nosso). 
Diante dos excertos apresentados, parece-nos necessária uma atenção redobrada para a proposta divulgada nos materiais com orientação aos professores. É certo que devem ocorrer mudanças tendo em vista as condiçóes atuais em que se encontra a educação pública, mas é preciso cautela quanto aos rumos escolhidos, pois as proposiçóes que se apresentam nessas orientações ao trabalho do professor parecem desconsiderar o valor dos currículos escolares e do saber sistematizado.

No que se refere às mudanças na organizaçáo pedagógica das escolas, o módulo apresenta que as "novas propostas de organização curricular convertem as disciplinas acadêmicas em meio e não em fins da educação escolar" (BRASIL, 2007c, p. 47).

A proposta para a organização do ensino na sala de aula regular, veiculada pelo material em análise, indica a adequação da aprendizagem ao que é "natural e espontâneo no processo de aprender e no desenvolvimento humano" (BRASIL, 2007c, p. 48). Ele considera que somente o aluno "é capaz de regular o seu processo de construção intelectual” (BRASIL, 2007c, p. 49). Assim, prevê a ação do professor e do aluno de forma que "cabe ao aluno individualizar a sua aprendizagem e isso ocorre quando o ambiente escolar e as atividades e intervençóes do professor o liberam, o emancipam, dando-lhe espaço para pensar, decidir e realizar suas tarefas, segundo seus interesses e possibilidades" (BRASIL, 2007c, p. 49).

O módulo Atendimento Educacional Especializado: Deficiência Mental (BRASIL, 2007), ao trazer orientaçóes aos professores do ensino regular para o trabalho especificamente junto ao aluno com deficiência mental, no capítulo "A escola comum diante da deficiência mental”, apresenta uma abordagem da aprendizagem, segundo a qual:

Aprender é uma ação humana criativa, individual, heterogênea e regulada pelo sujeito da aprendizagem, independentemente de sua condição intelectual ser mais ou ser menos privilegiada [...]. Essa diversidade deriva das formas singulares de nos adaptarmos cognitivamente a um dado conteúdo e dada possibilidade de nos expressarmos abertamente sobre ele. (BRASIL, 2007, p. 17).

Como vemos, rejeita as formas tradicionais de ensino em nome da defesa "pela construção do conhecimento", cuja perspectiva é de que as atividades escolares devem, supostamente, atender as expectativas individuais e imediatas do aluno.

As proposições para as salas regulares indicam ainda "atividades abertas [...] que possam ser abordadas por diferentes níveis de compreensão" e práticas voltadas para "o ensino de temas, de assuntos de interesse da turma” (BRASIL, 2007c, p. 53). Assim, os conteúdos das disciplinas são secundários, pois: 
[...] As atividades são exploradas, segundo as possibilidades e interesses dos alunos, após serem livremente escolhidas por eles. Debates, pesquisas, registros escritos, falados, observação, vivências são alguns processos pedagógicos indicados para a realização de atividades dessa natureza. Por meio destes e de outros processos pedagógicos, os conteúdos das disciplinas vão sendo espontaneamente chamados, para melhor esclarecer os temas/assuntos em estudo. (BRASIL, 2007c, p. 53).

Os argumentos contidos nos excertos acima conferem demasiada importância à espontaneidade. Assim, podem conduzir o processo de ensino-aprendizagem a uma prática descontínua e sem direcionamento, cuja regulação é atribuída como responsabilidade do próprio aluno. Com a defesa apresentada por uma dimensão fortemente subjetiva e individual para o processo de aprendizagem, corre-se o risco de promover um entendimento que ignora as características coletivas e históricas do desenvolvimento humano no que diz respeito aos processos de objetivação e apropriação.

Ao fazermos o contraponto com a Teoria Histórico-Cultural, compreendemos que as elaboraçôes obtidas pela humanidade são resultado de um longo processo de desenvolvimento que envolve geraçôes e a constituição das capacidades humanas em cada pessoa depende da apropriação dos resultados objetivados por essa coletividade (LEONTIEV, 1978). De acordo com a referida teoria, para se constituir individualmente é preciso, antes, desenvolver-se pelas relaçóes coletivas. $\mathrm{O}$ homem tem natureza social, assim como seu aprendizado. Qualquer pessoa isolada em si e colocada à sorte dos ímpetos espontâneos se reduz, devido ao esvaziamento das mediaçóes. Assim, à educação escolar, uma vez que assuma o compromisso com a emancipação humana, cabe organizar o ensino intencionalmente para retirar a criança do estado natural e impulsioná-la para as formas culturais de pensamento. Os conhecimentos espontâneos da criança devem ser ponto de partida, tendo em vista a elevaçáo rumo à elaboração dos conceitos científicos, e não objetivos finais do processo educacional.

A proposta de trabalho presente nos documentos do MEC, especificamente para o AEE na SRM, vem organizada em vários módulos, entre os quais destacamos $O$ Atendimento Educacional Especializado-Deficiência Mental. De modo geral, o módulo, que trata especificamente do trabalho da SRM para a área intelectual, apresenta proposiçóes situadas no mesmo sentido daquelas apresentadas para o ensino regular, anteriormente mencionadas, e, inclusive, ao tratar da prática do AEE para a área da "deficiência mental", expóe que o objetivo é "[...] propiciar condiçóes e liberdade para que o aluno com deficiência mental possa construir a sua inteligência, dentro do quadro de recursos intelectuais que lhe é disponível, tornando-se agente capaz de produzir significado/conhecimento" (BRASIL, 2007, p. 25, grifo nosso). 
Diante da condição diretiva que é atribuída à vontade do aluno, os encaminhamentos direcionados do professor parecem perder a valia e o significado, assim como há indicativos de que o próprio planejamento docente é abreviado, pois "[...] compreende a conversaçáo livre entre o professor e os alunos a respeito do tempo naquela jornada. Esse momento permite ao aluno expressar-se livremente a respeito do que pretende fazer/aprender naquele dia e a professora colocar suas intençóes no mesmo sentido" (BRASIL, 2007, p. 19).

Os argumentos expostos sugerem que a aprendizagem depende dos aspectos próprios de cada pessoa, o que faz lembrar uma perspectiva inatista acerca do desenvolvimento humano, de acordo com a qual as possibilidades dependem exclusivamente dos fatores internos, da determinação orgânica da criança. Nessa perspectiva, o documento expóe ser importante que:

[...] o aluno traga a sua vivência e que se posicione de forma autônoma e criativa diante do conhecimento, o professor sai do lugar de todo o saber e, assim, o aluno pode questionar e modificar sua atitude de recusa do saber e sair da posição de não saber. Ao tomar consciência de que não sabe é que o aluno pode se mobilizar e buscar o saber. A liberdade de criação e o posicionamento autônomo do aluno diante do saber permitem que sua verdade seja colocada, o que é fundamental para os alunos com deficiência mental. Ele deixa de ser o eco do outro e se torna um ser pensante e desejante de saber. (BRASIL, 2007, p. 24, grifo nosso).

Nota-se a indicação de uma busca por meio da qual a criança encontra respostas por si mesma. À luz da Teoria Histórico-Cultural e, mais especificamente, a partir do conceito de humanizaçáo desenvolvido por Leontiev (1978), compreendemos que o conhecimento não é construído individualmente, como defendem as orientaçôes em análise, mas pelo coletivo humano, que ao longo de geraçóes acumula experiências oriundas das relaçóes produtivas. Devemos considerar o valor do conhecimento sistematizado a ser apropriado pelo aluno, o que acontece por meio do planejamento e em decorrência de ação intencional e das mediaçóes do professor. Segundo as orientaçóes em análise,

O Atendimento Educacional Especializado não deve ser uma atividade que tenha como objetivo o ensino escolar especial adaptada para desenvolver conteúdos acadêmicos, tais como a Língua Portuguesa, a Matemática, entre outros. Com relação à Língua Portuguesa e a Matemática, o Atendimento Educacional Especializado buscará o conhecimento que 
permite ao aluno a leitura, a escrita e quantificação, sem o compromisso de sistematizar essas noçóes. (BRASIL, 2007, p. 26).

Nesse material, constata-se a defesa por abordagens que não dão ênfase ao compromisso com a apropriação de conhecimentos. Parece-nos que o destaque se situa sobre a socialização, entendida como convivência com os pares da mesma idade. A mediação docente não recebe a evidência necessária no processo de ensinoaprendizagem. Reforça-se, em vários momentos, a defesa pelo conhecimento construído pelo aluno e, ainda:

O Atendimento Educacional Especializado tem de estar desvinculado da necessidade típica da produção acadêmica. A aprendizagem do conteúdo acadêmico limita as açôes do professor especializado, principalmente quanto ao permitir a liberdade de tempo de criação que o aluno com deficiência mental precisa ter para organizar-se diante do desafio do processo de construção do conhecimento. Esse processo de conhecimento, ao contrário do que ocorre na escola comum, não é determinado por metas a serem atingidas em uma determinada série, ou ciclo, ou mesmo etapas de níveis de ensino ou de desenvolvimento.

O processo de construção do conhecimento, no Atendimento Educacional Especializado, não é ordenado de fora, e não é possível ser planejado sistematicamente obedecendo a uma sequência rígida e predefinida de conteúdos a serem assimilados. E assim sendo, não persegue a promoção escolar, mesmo porque esse aluno já está incluído. (BRASIL, 2007, p. 26).

$\mathrm{Na}$ busca por uma especificidade para o AEE, diferenciando-o do trabalho realizado na sala regular, há, nos documentos em análise, a defesa de que, nesse atendimento, deve-se aprender algo diferente dos conteúdos.

Nota-se o entendimento de que para aprender, supostamente é preciso uma preparaçấo, uma organização do sujeito em momento anterior à apropriação do conhecimento. Esse entendimento aponta para a afinidade com um referencial que separa aprendizagem e desenvolvimento, como se o segundo antecedesse o primeiro, ou seja, entende que para aprender é preciso antes trabalhar as áreas do desenvolvimento, como atenção, memória, entre outras. Vigotski (1998) afirma que essa compreensão está presente na concepção de Piaget, para a qual não há intercâmbio entre desenvolvimento e aprendizagem e sim uma preeminência do desenvolvimento que o faz preceder a aprendizagem. 
A partir da Teoria Histórico-Cultural, no entanto, evidenciamos que a aprendizagem impulsiona o desenvolvimento e o antecede. $\mathrm{O}$ ensino, de acordo com esse referencial, deve levar à aprendizagem, o que, consequentemente, movimentará o desenvolvimento do sujeito, inclusive com deficiência intelectual.

O módulo que aborda o AEE para alunos com deficiência intelectual divulgado pelo MEC em 2010 apresenta o atendimento a ser direcionado ao aluno e concebe a avaliação numa articulação entre o AEE e a sala comum. Além disso, tal módulo divulga estudos de caso que demonstram a elaboração do plano de AEE.

Em carta inicial direcionada aos leitores, o trabalho do professor do AEE na SRM é apresentado, por esse documento, em três polos: "gestão dos processos de aprendizagem, avaliação e acompanhamento" (BRASIL, 2010, p. 6). Nota-se de imediato que em nenhum desses eixos há menção do ensino. A "gestão da aprendizagem”, que mais poderia se aproximar ao ensino, na verdade refere-se à:

[...] organizaçáo de situações de aprendizagem nos espaços das salas de recursos multifuncionais, bem como na interlocução com o professor do ensino comum [...]. Para potencializar o desenvolvimento e a aprendizagem do aluno com deficiência intelectual, o professor deverá usar recursos de baixa e alta tecnologia, selecionar e produzir materiais. (BRASIL, 2010, p. 9).

Pode-se inferir que há uma ênfase nas atividades organizativas, de produção de material e de proposição de recursos tecnológicos. A atividade pedagógica direcionada, relacionada ao ensino propriamente dito, não é contemplada entre as funçóes pelo professor. Portanto, os argumentos anunciados levam a supor que a aprendizagem é considerada como um processo autônomo, regulado pelo próprio aluno; o professor, quando muito, vai eliminar as barreiras que dificultam a aprendizagem. Além disso, não está claro o que é posto como objeto da aprendizagem do aluno, uma vez que a apropriação de conteúdos não é mencionada.

O processo de desenvolvimento humano, de acordo com a Teoria HistóricoCultural, está associado aos fatores socioculturais que envolvem toda a coletividade humana. Rossetto (2012, p.55), fundamentada nesse referencial, argumenta que “[...] o indivíduo se constitui como sujeito por meio de um processo permanente de interaçóes compartilhadas e que seu desenvolvimento é concebido à luz das inter-relaçôes e das circunstâncias culturais, sociais e históricas".

Além disso, de acordo com esta autora, "a abordagem Histórico-Cultural nos oferece uma visão de sujeito que não se resume às suas incapacidades, mas aposta nas possibilidades" (ROSSETTO, 2012, p. 55). 
A atribuição de centralidade às atividades espontâneas das crianças sem direcionamento de um mediador pode resultar em poucas perspectivas para a escolarização da pessoa com deficiência intelectual. Projetar apenas a convivência no ambiente escolar e a aprendizagem espontânea, sem ênfase ao direcionamento pedagógico indica a subestimação das possibilidades da pessoa com deficiência intelectual em superar os obstáculos apresentados pela deficiência.

Assim como a Teoria Histórico-Cultural, as proposiçôes do MEC defendem a superação do modelo clínico e da abordagem meramente biológica na educação das pessoas com deficiência. No entanto, a primeira introduz a apropriação dos conhecimentos como fator determinante do desenvolvimento humano, o que indica a relevância da mediação e dos conteúdos escolares, enquanto as divulgações do governo parecem reduzir sua proposta de trabalho docente de modo que a centralidade é atribuída àquilo que o aluno realiza por si mesmo.

Nos argumentos da publicação do MEC (2010), a ênfase na construção do conhecimento por parte do aluno contempla, inclusive, o processo avaliativo individualizado na SRM e denota náo dar importância ao ensino dos conteúdos nem a avaliação da apropriação, pois a intenção é identificar a evolução do aluno e a sua "relação com o saber". Cabe ao professor do AEE "conhecer o que o aluno sabe em função de suas experiências de vida” (BRASIL, 2010, p. 12). No acompanhamento a ser realizado na SRM, propóe-se que o professor "organize situaçóes de aprendizagem a partir dos interesses manifestados pelo aluno e escolhas diante das possibilidades existentes" (BRASIL, 2010, p. 15).

Os propósitos presentes nos textos de 2010 seguem a mesma linha de pensamento dos documentos divulgados nacionalmente pelo MEC em 2007 (abordados anteriormente): apontam para uma conotaçáo espontaneísta para os processos de ensino e de aprendizagem; recomendam à ação docente proposiçóes pedagógicas sem garantia de um direcionamento, nas quais o aluno decide o que convém desenvolver; enfatizam o interesse do aluno e, em consequência, podem permitir a secundarização do ensino; e, principalmente, não articulam o trabalho do AEE na SRM dos conteúdos escolares.

A abordagem apresentada nos discursos em análise parece-nos próxima das características presentes nos preceitos da Escola Nova, do Construtivismo, bem como afinadas ao pensamento pós-moderno, tendo em vista que esses referenciais abrem espaço para a fragilização do ato de ensino, o apelo à liberdade do aluno, a supressão dos conteúdos escolares, a defesa da aprendizagem espontânea e a negaçáo dos métodos tradicionais de ensino. 
Duarte $(2005$, p. 87) defende a tese de que "o construtivismo e o pósmodernismo pertencem a um mesmo universo ideológico e as interfaces entre ambos são tantas e em aspectos táo fundamentais que, em muitos momentos, não faz diferença caracterizar o pensamento de um autor como construtivista ou como pós-moderno". Nesse sentido, Derisso (2010), defende haver uma continuidade que passa pelo desenvolvimento das pedagogias ativas do movimento Escola Nova, pelo construtivismo e pela pedagogia das competências que, embora nem sempre assumida, expressa o pensamento pós-moderno.

Lembremos que a Escola Nova foi demarcada por Saviani (2003) no âmbito da pedagogia dominante, reconhecida como pedagogia de inspiração liberal, que defende um tratamento diferenciado a partir das diferenças individuais. Em contraposição a uma pedagogia emancipatória, a Escola Nova promoveu o rebaixamento do nível de ensino da classe trabalhadora (SAVIANI, 2003). Devido ao seu entendimento acerca da educação, compreende-se que ela

[...] tenha deslocado o eixo da questão pedagógica do intelecto para o sentimento, do aspecto lógico para o psicológico, dos conteúdos cognitivos para os métodos ou processos pedagógicos, do professor para o aluno, do esforço para o interesse, da disciplina para a espontaneidade, do diretivismo para o não-diretivismo, da quantidade para a qualidade, de uma pedagogia de inspiração filosófica centrada na ciência para uma pedagogia de inspiração experimental baseada principalmente nas contribuiçôes da biologia e da psicologia. (SAVIANI, 2003, p. 9).

O Construtivismo, por sua vez, possui como referência a epistemologia genética de Piaget e, segundo Duarte (1998, p. 7), "retoma em outras roupagens muitas das ideias fundamentais da Escola Nova”. De acordo com o autor, está entre as concepçóes pedagógicas que "[...] respaldam-se em teorias psicológicas que valorizam as aprendizagens que o indivíduo realiza sozinho, como qualitativamente superiores àquelas onde o individuo assimila conhecimento através da transmissão de outras pessoas" (DUARTE, 1998, p. 6).

Assim, sob o entendimento construtivista, o papel do professor é diluído, pois cabe a este apenas acompanhar e, no máximo, proporcionar as condiçóes e situaçôes desafiadoras para o desenvolvimento do aluno (DUARTE, 1998). Portanto,

É interessante notar que tanto no Construtivismo como na Escola Nova, assumiram um acento de valor claramente negativo o verbo ensinar e a expressão "transmissão de 
conhecimentos". O professor é reduzido a um "animador", a alguém que fornece condições para que o aluno construa por si mesmo o conhecimento. Para náo ser reduzido a um mero enfeite do processo educativo, pode até, "eventualmente", fornecer alguma orientação para o aluno. (DUARTE, 1998, p. 9).

O pensamento pós-moderno, por sua vez, faz a defesa pela cultura cotidiana, instaura a crítica à razão, exacerba a subjetividade e, por meio do relativismo (forte elemento do pensamento pós-moderno), recusa a objetividade do conhecimento. Essa condição provoca a redução teórica que incide sobre a educação atualizando-a aos moldes do capitalismo globalizado, o que faz do "aprender a aprender" 5 um lema conveniente (DUARTE, 2006).

Não é por coincidência que o vocabulário que deriva desse universo ideológico (Escola Nova, Construtivismo e pensamento pós-moderno) é comum à linguagem que compóe as proposiçóes pedagógicas divulgadas pelo MEC. Há indicativos decerta afinidade entre os discursos que possivelmente decorrem das exigências postas pelas transformaçôes da base material da sociedade, em que a globalização econômica determina a adequação de todas as esferas da vida humana à lógica de mercado.

Com a adesão à perspectiva das pedagogias do "aprender a aprender" é feita a defesa de uma educação ao longo da vida, que esteja vinculada a uma formação pragmática e imediata. $\mathrm{O}$ sujeito adequado às novas demandas da esfera produtiva precisa de uma educação flexível que o prepare para aprender sempre, como forma de estar constantemente atualizado relativamente às novas condiçóes do mundo do trabalho, as quais são impulsionadas por frequentes avanços tecnológicos e inovaçóes científicas.

Essa filiação teórica não é assumida, mas, em geral, está presente nos discursos dos documentos e é compatível com a intencionalidade que os compóe. É uma marca da educação direcionada pela ideologia hegemônica para a escola pública. Concordamos com Duarte (2006), conforme o qual, a ação de desconsiderar os conteúdos do ensino desvaloriza o próprio ato de ensinar.

Considerando o contexto histórico em que se dá a formação do professor para as práticas inclusivas, com base nos padrôes atuais de formação de professores no Brasil, chama a atençáo o fato de que nas últimas décadas retomam-se na formação da grande maioria dos docentes, princípios pedagógicos associados ao "aprender a aprender" (DUARTE, 2006), que ascenderam no Brasil com o movimento escolanovista. Os professores, assim como os alunos, aprendem a aprender por meio de um sistema de formação massificado e superficial. Tal abordagem está presente na formação dos 
professores da Educação Básica e, conforme constatamos, a formação para o AEE também é atingida - assim, pode ser tomada como parte dessa realidade.

Duarte (2006, p. 8), frente às diversas proposiçôes desse cunho teórico que ganham espaço na educação contemporânea, alerta-nos para a "desvalorização da transmissão do saber objetivo" e a "diluição do papel da escola em transmitir esse saber", além da "descaracterização do papel do professor como alguém que detém um saber a ser transmitido aos seus alunos". Martins (2010, p. 52), diante de modelos educacionais que desprezam o trabalho com os conteúdos, indica que:

[...] ao preterirem a transmissão de conhecimentos básicos indispensáveis a uma formação intelectual que assegure o domínio da cultura letrada de base científica, aprisionam os indivíduos nos limites das funçóes psicológicas elementares que se caracterizam pelo domínio das relações espontâneas e a decorrente formação de conceitos também espontâneos.

Nessa direção, Facci (2004) discute as consequências trazidas pela formação de professores sob a influência dos referenciais construtivistas e nos apresenta, entre outras preocupaçóes, o fato de o ato de ensinar náo ser enfatizado. $\mathrm{O}$ tratamento direcionado ao ensino nos documentos em análise se aproxima ao relacionado pela referida autora. O ensino é colocado em plano secundário enquanto o desenvolvimento natural do aluno se torna a diretriz da aprendizagem.

Enfim, com base nos argumentos expostos, consideramos que a concepção de desenvolvimento humano, de mediação (ensino) e de aprendizagem subjacentes às proposiçóes divulgadas em nível nacional pelo MEC diverge dos pressupostos que constituem a Teoria Histórico-Cultural. O trabalho docente indicado para a SRM junto a alunos com deficiência intelectual, por refletir a condição mais ampla colocada para o trabalho na sociedade capitalista, defronta-se com significativos obstáculos para contribuir com possibilidades que se coloquem favoráveis à "humanização" (LEONTIEV, 1978) desses sujeitos.

\section{A deficiência intelectual e os processos compensatórios}

A deficiência intelectual, desde os períodos primitivos, foi compreendida de diferentes formas, considerada incapacidade, demência e até loucura. No momento atual, obtivemos uma grande diferenciação na consideraçáo dessas pessoas, mas os diversos entendimentos ainda permanecem vivos, embora de forma menos intensa. Assim, há momentos em que aparecem em um ou outro espaço, ainda que, certamente, 
tenhamos compreensóes e denominaçóes mais aceitas e correspondentes a visões mais humanas.

O referencial histórico-cultural nos proporciona a compreensão de que é a inserção na cultura que orienta e altera os rumos do desenvolvimento psíquico. De acordo com Padilha (2005, p. 3-4) "não há limitação previsível de incorporação cultural. Tudo que envolve o homem é humano e cultural, com limites desconhecidos". Assim, a perspectiva de que o desenvolvimento humano náo pode ser prescrito é de grande relevância para a educação da pessoa com deficiência.

O defeito ${ }^{6}$ desempenha uma dupla ação no desenvolvimento humano: produz faltas, empecilhos e dificuldades; mas também impulsiona para a conquista de caminhos alternativos (indiretos), para a superposição de energia que não só elimina a fraqueza, como resulta em força extra, pois "o comportamento cultural sobrepóe-se ao comportamento cultural defeituoso" (VYGOTSKY; LURIA, 1996, p. 221). O organismo não somente compensa o prejuízo, como também produz o excesso, uma superioridade. Assim, "o defeito deixa de ser considerado apenas insuficiência e se converte em estímulo para a supercompensação" (VYGOTSKY; LURIA, 1996, p. 222223).

De acordo com Rossetto (2009, p. 46), por meio do "mecanismo de compensação [...] existe a possibilidade da pessoa com deficiência ultrapassar a limitação orgânica e seguir o curso de seu desenvolvimento". Portanto, na compreensão dos processos compensatórios reside uma significativa orientação para a educação escolar e, sem dúvida, para a educação especial. A partir desse conceito, compreende-se que a educação da criança deve basear-se no fato de que "a compensação não se refere à eliminação do déficit, nem é de ordem sensorial ou motora. A força motriz dos processos compensatórios advém da vida social, da oportunidade de acesso à cultura, do desenvolvimento das funçôes psicológicas superiores" (ROSSETTO, 2012, p. 66).

Portanto, simultaneamente à deficiência, estão dadas as tendências psicológicas de uma orientação oposta e, a partir dessa compreensão, abrem-se as possibilidades de uma organização para superação, a ser incluída no processo educacional. Nesse sentido, diante do propósito de pensar a educação para a pessoa com deficiência intelectual, destacamos a relevância dos processos compensatórios. Mas como seria a compensação para a pessoa com deficiência intelectual?

Para o surdo, para o cego ou para a pessoa com deficiência física, parece-nos mais previsível. Nesses casos, o uso de vias colaterais é um fator decisivo e o reequipamento cultural apresenta-se, de certa forma, mais claro, mas quais as vias colaterais a serem utilizadas para a pessoa com deficiência intelectual e como pode se dar o seu reequipamento cultural? $\mathrm{O}$ esclarecimento desses conceitos (compensação, vias 
colaterais e reequipamento cultural) e a consideração de como relacioná-los com a área da deficiência intelectual são significativos para pensarmos acerca do AEE.

Os processos compensatórios estão relacionados à disposição interna da pessoa e ao meio em que estiver inserida, simultaneamente. Assim, a relação estabelecida entre os fatores biológicos e culturais estabelece que o defeito é orgânico, mas a deficiência é social (CARVALHO, 2009), ou seja, a pessoa com defeito será deficiente se diminuída à sua condição biológica, pois, uma vez considerada a amplitude das alternativas de compensação e proporcionado o aparato cultural, os efeitos sociais do defeito podem ser superados. Esse entendimento nos remete à importância de compreender o desenvolvimento humano e visualizar o que há de específico para a pessoa com deficiência intelectual, tanto no que diz respeito à forma como ocorre o desenvolvimento psíquico quanto às necessidades desse processo.

O desenvolvimento humano acumula-se dando origem aos "instrumentos culturais", portanto, estes resultam da própria atividade humana e carregam em si significados que representam o ganho histórico obtido pelos homens em suas atividades coletivas (LEONTIEV, 1978). A apropriaçáo dos significados desses instrumentos pelas novas geraçóes proporciona as possibilidades de internalização dos resultados da atividade intelectual das geraçóes anteriores. Por esse meio, o homem absorve o saldo de toda uma evolução histórica e apropria-se de resultados que não poderia obter individualmente. Esse processo, no entanto, náo ocorre de modo espontâneo ou incidental, mas se dá pela aprendizagem, pelas diversas mediaçôes a que o sujeito está disposto.

De acordo com Leontiev (1978), a aprendizagem se dá para o indivíduo de modo relacionado com o meio no qual está inserido. Dessa forma, ocorre o desenvolvimento psíquico e o sujeito se apropria das aquisiçóes das geraçóes humanas precedentes. Assim sendo, "[...] o processo realiza-se na atividade que a criança emprega relativamente aos objetos e fenômenos do mundo circundante, nos quais se concretizam estes legados da humanidade" (LEONTIEV, 1978, p. 323).

A assimilação dos signos presentes nos instrumentos culturais, mediados no espaço escolar, transforma as funçôes naturais da criança. Assim, à educação cabe impor novo ritmo e modificar o curso ao desenvolvimento que se apresenta lento. Portanto, as atividades educacionais náo devem colocar-se no âmbito da espontaneidade e acompanhar as possibilidades imediatas da criança, mas adiantar-se, pois a aprendizagem antecede e impulsiona o desenvolvimento.

Vigotski (1983) fez a defesa da educabilidade da pessoa com deficiência, a partir da consideração de que o problema não está no defeito, mas na ausência de uma educação adequada, que atue nas consequências sociais do defeito. O plano educativo 
deve basear-se em uma "caracterização positiva" da criança, e "la pedagogía tiene que orientarse no tanto hacia la deficiencia y la enfermedad, como hacia la norma y la salud que se conserva en el niño" (VIGOTSKI, 1983, p. 141).

Para a superação do atraso presente no desenvolvimento da pessoa com deficiência intelectual é preciso considerar que, embora existam especificidades, as "formaçôes" que se originam a partir do processo educativo podem proporcionar a superação da base primária da deficiência intelectual. O defeito ainda existe, mas se apresenta de forma distinta e permite o desenvolvimento daquele sujeito (VIGOTSKI, 1983).

De acordo com Vigotski (1983), compreendemos que uma criança com comprometimento tem maior necessidade que as outras de acesso à educação. Para ela, o acesso à cultura precisa se organizar de forma mais intensa, mais firme em seus propósitos.

Os processos compensatórios relacionam-se e são influenciados pela consciência da pessoa acerca do defeito e da falta decorrente deste. É essa percepção que permite a mobilização das forças para a superação do déficit. Com relação à pessoa com deficiência intelectual, náo ocorre, necessariamente, a percepçáo acerca da carência. Nesse caso, o ímpeto para a compensação pode ser determinado pela convivência coletiva em sociedade; o comportamento existe primeiramente em decorrência das relaçóes sociais estabelecidas e, posteriormente, torna-se pertencente à conduta particular e individual do sujeito (BARROCO, 2007).

A passagem das funçóes elementares às superiores é essencial para o processo de "humanização" (LEONTIEV, 1978). A constituição dessas funções que são consideradas mais avançadas fornece a cada sujeito as capacidades eminentemente humanas, como a condiçáo de controlar o comportamento involuntário, o direcionamento da atenção, o desenvolvimento de formas de memória mediada, entre outros. Ergue-se, sobre a forma natural de homem, a alternativa cultural, condição em que a constituição da consciência distingue com veemência a espécie humana da natureza animal. Esse processo se dá por meio da apropriaçáo dos resultados da atividade intelectual, acumulada e expressa nos signos sociais, ou seja, pela apropriaçáo da cultura.

No âmbito escolar, a cultura é organizada por meio dos conteúdos escolares, os quais podem promover o desenvolvimento das funçôes psicológicas superiores dos alunos. Para a criança com deficiência intelectual, cujo desenvolvimento das funçóes avançadas se dá de forma mais lenta, faz-se necessário o uso de instrumentos culturais e a intensificação das mediaçôes no sentido de agilizá-las. De acordo com Vigotski (1983, p. 118), 
Aunque los niños atrasados mentales estudian un tiempo más prolongado, aunque ellos aprendan menos que los niños normales y, por último, aunque se les enseñe de otra manera, aplicando métodos y procedimientos especiales, adaptados a las particularidades de sus estados, ellos aprenderán lo mismo que todos los demás nińos y recibirán la misma preparación para la vida futura [...].

Observamos que o tempo e as mediaçóes necessárias para conseguir determinados resultados se diferenciam de uma criança para outra. No entanto, o percurso do desenvolvimento da criança com deficiência é o mesmo de outras crianças. Nesse sentido, "Vigotski discute o processo de desenvolvimento humano na perspectiva de que as leis do desenvolvimento são as mesmas para todas as crianças" (ROSSETTO, 2009, p. 33).

Ao assumirmos o pressuposto de que todo ser humano aprende e todo aprendizado é mediado, comprovamos a relevância da educação escolar como mediação intencional e planejada que impulsiona o desenvolvimento. Consideramos, também, a importância assumida pela ação pedagógica para a apropriação dos conteúdos escolares, pois o desenvolvimento das funçóes psicológicas superiores é impulsionado pela aprendizagem que promove o desenvolvimento. Luria (2008), a partir das pesquisas desenvolvidas nos anos de 1931 e 1932 (período de reorganização mais radical da União Soviética), constata que:

A estrutura da atividade cognitiva não permanece estática ao longo das diversas etapas do desenvolvimento histórico e as formas mais importantes de processos cognitivos - percepção, generalização, dedução, raciocínio, imaginação e auto-análise da vida interior - variam quando as condiçóes de vida social mudam e quando rudimentos de conhecimento são adquiridos. (LURIA, 2008, p. 215).

Segundo Sforni (2008, p. 4), ao se apropriar dos conhecimentos, "[...] cada ser humano incorpora o desenvolvimento intelectual e ideal neles presente". Em outros termos, o homem apropria-se da capacidade intelectiva elaborada na construção dos bens culturais ao longo da história por meio da apropriação dos instrumentos culturais e dos resultados da objetivação humana. Nesse processo, a mediação assume grande relevância.

Rossetto (2009, p. 40) afirma que "o conceito de mediação é central para explicar a conversão das funçôes naturais em funções culturais do ser humano”. A mediação no campo escolar tem implicaçóes concomitantes à importância da abordagem dos conteúdos escolares, pois: 
[...] no contexto escolar há uma dupla mediação, uma que se refere à relação entre professores e estudantes, outra vinculada à relação entre os estudantes e o conteúdo escolar. Do ponto de vista do desenvolvimento psíquico, a primeira somente se realiza quando a ação docente envolve a disponibilização dos conteúdos escolares como mediadores da ação dos estudantes, isto é, de modo que eles sejam capazes de realizar conscientemente as açóes mentais objetivadas nos conhecimentos historicamente produzidos. (SFORNI, 2008, p. 7).

Considera-se, a partir da "dupla mediação", a relevância tanto da ação pedagógica quanto dos conteúdos. Não é qualquer atividade que promove o desenvolvimento cognitivo humano; é necessária a mediação intencional e a abordagem dos saberes formais.

$\mathrm{Na}$ escola, o conhecimento organizado por meio dos conteúdos escolares constitui-se em mediador cultural que atua no desenvolvimento humano. $\mathrm{O}$ professor também estabelece mediaçóes, sendo que estas são vinculadas diretamente à abordagem dos conteúdos. Considera-se, assim, que o trabalho educativo escolar não se trata de qualquer ação; é imprescindível intencionalidade e organização adequada com fins direcionados. Conforme Sforni (2008, p. 5), "as açóes e operações requeridas, bem como a formação das faculdades necessárias à sua realização apenas são desenvolvidas na criança porque a relação que ela estabelece com os objetos é mediatizada por outros seres que já se apropriaram desses objetos".

Com base nos argumentos acima apresentados, a aprendizagem dá-se por meio da atividade orientada/mediada pelo educador (alguém mais experiente). Então, “ao educador cabe a função de propor motivos que desvendem atividades que tenham sentido para a criança, de tal modo o educador faz a ponte de ligaçáo da criança com o mundo da cultura” (SOUZA, 2007, p. 85).

Nesse entendimento, os conteúdos escolares promovem e impulsionam o uso de caminhos indiretos, visto que proporcionam à criança a possibilidade de atuar com recursos psicológicos (funções) adquiridos por meio da internalização dos signos culturais. Assim, os sujeitos passam a utilizar estratégias apreendidas que não seriam capazes de obter sozinhos e que modificam sua relação com o mundo. Esse processo ocorre também na pessoa com deficiência intelectual, ou seja, a relação com os saberes formais atua no sentido de modificar as condiçóes naturais de sua consciência.

Os obstáculos presentes nas atividades propostas pela ação mediadora do professor levam a criança a novos patamares de desenvolvimento. Quando ela faz uso de determinado raciocínio, cabe ao professor impor-lhe novos desafios, ou seja, organizar 
impedimentos para o caminho direto, para o seu raciocínio usual, forçando a abertura de novas vias. Portanto, o desenvolvimento das formas superiores de comportamento acontece sob a pressáo da necessidade oriunda da mediaçáo estabelecida nas relaçôes sociais e na educação.

Lembremo-nos de que a educação é parte significativa das relações estabelecidas socialmente. Assim, ela ganha destaque no desenvolvimento humano e se torna indispensável para a pessoa com deficiência, sendo que esta deve estudar os mesmos conteúdos das outras pessoas, ainda que precise de uma metodologia especial. Nesse sentido,

Deve-se considerar que o sujeito com deficiência é, antes de tudo, um sujeito, que se desenvolve de maneira peculiar. Como qualquer ser humano possui uma singularidade, isto é pode alcançar os mesmos níveis de desenvolvimento de uma criança que não apresenta deficiência, porém, por meio de outros caminhos (ROSSETTO, 2012, p. 67).

Assim, reiteramos a necessidade de condiçóes diferenciadas das pessoas com deficiência, a fim de entender a importância que pode assumir a SRM, pois "quanto mais oportunidade de acesso a pessoa com deficiência tiver aos meios educacionais, melhor se desenvolverá, desde que seja dado o suporte às suas necessidades" (ROSSETTO, 2012, p. 67).

Vigotski (1983), ao discorrer acerca da organização do ensino especial, discorda da forma como estava organizado e das práticas em vigor, nomeando-as de enfadonhas, silenciosas e desarticuladas das necessidades sociais dos alunos, mas defende a relevância do processo educativo com propósitos e uma organização distinta:

[...] cómo no decir que estas mismas clases de silencio, pero no por equipo ni establecidas sin un propósito, sino provocadas por cierta necesidad de jugar, llenas de sentido y reguladas por el mecanismo del juego, pierden de pronto el carácter de suplicio forzado y pueden ser un maravilloso medio educativo. (VIGOTSKI, 1983, p. 137).

Se a falta da educação ou o direcionamento de encaminhamentos incoerentes são prejudiciais ao desenvolvimento do aluno com deficiência intelectual, por outro lado, um processo educacional no qual haja propósitos sólidos e boa organização pedagógica é fortalecedor das capacidades de superação dos limites impostos pela deficiência. No entanto, dada a sobrevalência dos interesses hegemônicos para manter as determinaçóes objetivas da sociedade capitalista, a educação direcionada aos sujeitos 
da classe trabalhadora volta-se para a formação de uma consciência alienada e para a constituição de capacidades circunscritas à resolução de problemas simples e imediatos em detrimento da ampliação da capacidade intelectiva.

Com base na discussão estabelecida acerca da proposta para o trabalho docente na SRM, frente aos pressupostos do desenvolvimento da pessoa com deficiência, aqui apresentados, podemos inferir que as proposiçóes divulgadas pelos documentos representativos da educação especial na perspectiva da educação inclusiva se distanciam das condiçóes favoráveis para que os alunos com deficiência intelectual possam desenvolver as capacidades mais avançadas de pensamento.

Essa situação de cerceamento cultural é uma condição que contempla a classe trabalhadora como um todo. Ela não é exclusiva da pessoa com deficiência intelectual, mas nesta as consequências são ainda mais intensas, pois são reduzidas as possibilidades de que a educação formal, instituída na escola, contribua para a humanização. Assim, esse grupo de pessoas enfrenta consequências comprometedoras perante a redução da educação que lhes é proposta, dada a relevância das apropriações culturais para projetarse para além da deficiência.

\section{Considerações finais}

Com a análise dos materiais orientadores e formativos publicados pelo MEC e divulgados no site desse órgão, constatamos que as orientaçôes para o trabalho docente junto a alunos com deficiência intelectual apresentam uma concepção de aprendizagem e de ensino que indica ênfase nas atividades espontâneas em detrimento do direcionamento do professor. Podemos constatar, ainda, que a atividade de ensino não é prioridade nos documento se que o destaque é direcionado para a gestáo da aprendizagem, em que o professor se torna o organizador de situaçóes para que o aluno desenvolva sua aprendizagem livremente.

Outro aspecto recorrente nos documentos é a defesa pela construção do saber por parte do aluno, o que acena para a desconsideração de que o conhecimento resulta das objetivaçóes humanas cristalizadas nos instrumentos culturais, bem como a preterição da necessidade de apropriação do conhecimento para a construção das capacidades cognitivas mais avançadas.

Ao longo do discurso apresentado nos documentos, é intensa a persuasão que indica a secundarização do trabalho com os conteúdos, expressa pela crítica à valorização do saber sistematizado e pelo destaque da relaçáo individual que o aluno estabelece com o saber. Na perspectiva de tais documentos, parece que o significado arbitrário atribuído pelo aluno tem mais relevância do que o próprio conhecimento em 
si. Do mesmo modo, o interesse do aluno é valorizado como expressão da individualidade e tem centralidade no encaminhamento das atividades, suprimindo o direcionamento planejado do professor. Assim, náo se trata do interesse do aluno na condiçáo de classe social, mas da vontade imediata, desprovida de intencionalidade.

Nesse sentido, o quadro argumentativo expresso nos documentos publicados e veiculados pelo MEC para orientaçáo ao trabalho docente junto a alunos com deficiência intelectual na SRM parece-nos compatível com os princípios presentes no Construtivismo, ajusta-se aos propósitos pedagógicos da Escola Nova e relaciona-se ao relativismo próprio do pensamento pós-moderno, tendo em vista que, de acordo com Duarte (2005), estes são referenciais pertencentes ao mesmo universo ideológico.

Os argumentos que definem o ensino e a aprendizagem por uma concepção de desenvolvimento humano espontaneísta, de acordo com a qual o próprio aluno regula seu desenvolvimento, podem esvaziar as mediaçóes inerentes ao processo de escolarização.

Alerta-nos, no entanto, a intensidade das consequências de tal referencial diante do trabalho específico junto ao aluno com deficiência intelectual, pois, na perspectiva da Teoria Histórico-Cultural, está no conhecimento um relevante meio de compensação social para esse aluno, direcionado à superação das características biológicas impostas pela própria deficiência.

A contribuição dessa teoria psicológica para o campo pedagógico nos permitiu compreender, portanto, que as apropriaçôes culturais, expressas no espaço escolar pelo saber formal, elevam as possibilidades de desenvolvimento das funçóes psicológicas superiores e colaboram com a humanização. Em contrapartida, a retirada dos conteúdos tende à redução do sujeito aos limites da condição orgânica, determinada pela deficiência.

Duarte (2006), apoiado nas discussóes de Saviani (1997), diante dessa tendência teórica, defende a "resistência ativa", constituída por meio da organização coletiva, para que a educação da classe trabalhadora não seja reduzida à cultura do cotidiano imediato e apoiada em "concepçôes do conhecimento humano como algo particularizado, fragmentado, subjetivo, relativo e parcial que, no limite, negam a possibilidade de um conhecimento objetivo" (DUARTE, 2006, p. 10). O autor defende a luta por uma educação:

[...] que amplie os horizontes culturais desses alunos; [...] que produza nesses alunos necessidades de nível superior, necessidades que apontem para um efetivo desenvolvimento da individualidade como um todo; [...] que transmita aqueles conhecimentos que, tendo sido produzidos por seres humanos 
concretos em momentos históricos específicos, alcançaram validade universal e, dessa forma, tornam-se mediadores indispensáveis na compreensão da realidade social e natural o mais objetivamente que for possível no estágio histórico no qual encontra-se atualmente o gênero humano. (DUARTE, 2006, p. 10).

Nesse sentido, consideramos que há um espaço de contramão para a ação educativa. Embora não possamos mensurar, por meio deste estudo, a que medida esse espaço esteja sendo utilizado pelos professores, cumprimos a tarefa de colaborar para a apresentação das contradiçóes e dos condicionantes que permeiam o discurso das orientaçóes emitidas para o desenvolvimento do trabalho docente.

Compreendemos que a educação, sob os moldes do capitalismo, responde às demandas da manutenção social, que na atualidade anseiam pelo aprofundamento das formas de exploração. No entanto, a subordinação exercida pelos padróes dessa forma de organização social não é absoluta, pois a própria existência do trabalhador indica seu exercício de luta (MARX; ENGELS, 1998). Assim, apontamos ainda a necessidade de buscar, por meio de novas pesquisas, possibilidades para o trabalho docente na SRM que discutam as orientaçóes divulgadas pelo MEC, bem como obtenham uma gama maior de proposiçóes que possam enriquecer a ação docente. Reiteramos a importância da luta pela humanização, mesmo no interior da sociedade capitalista, como uma forma de se contrapor a esta organização social, conforme pensamento enfatizado no estudo da Teoria Histórico-Cultural, cujos fundamentos indicam o papel relevante da educação na constituição dos sujeitos.

Consideramos, portanto, que o AEE, constituído no bojo da sociedade capitalista, contém as marcas da realidade que o determina e carrega em si contradiçóes cuja visualização é necessária. Entendemos, porém, que, embora não tenhamos nos lançado ao desafio de pensar o trabalho docente na SRM para além das proposiçóes divulgadas pela via ministerial, esse é um exercício necessário para pensarmos o trabalho docente no intuito de posicioná-lo de forma a colaborar para a emancipação dos sujeitos com deficiência intelectual. Apontar as contradiçóes da proposta vigente, como foi objeto desta pesquisa, deu-se como um passo necessário e disparador de novas investigaçóes.

\section{Notas}

1 Endereço eletrônico: <http://portal.mec.gov.br/secretaria-de-educacao-continuadaalfabetizacao-diversidade-e-inclusao/publicacoes $>$. 
2 Coletânea Atendimento Educacional Especializado. Disponível em: <http://portal.mec.gov.br/secretaria-de-educacao-continuada-alfabetizacaodiversidade-e-inclusao/publicacoes?id=17009>.

3 Coleção A Educação Especial na Perspectiva da Inclusão Escolar. Disponível em: $<$ http://portal.mec.gov.br/secretaria-de-educacao-continuada-alfabetizacaodiversidade-e-inclusao/publicacoes?id=17009>.

4 Embora na atualidade a nomenclatura mais aceita seja "deficiência intelectual", utilizamos a designação "deficiência mental" nas situaçóes em que está presente nos documentos em análise.

${ }^{5}$ Termo empregado, primeiramente, por Delors (1998) e discutido por Duarte (2006) ao se referir às apropriaçôes neoliberais e pós-modernas da teoria vigotskiana. Este autor relaciona tal máxima às perspectivas teóricas que têm entre suas características a desvalorização do conhecimento científico na educação.

${ }^{6}$ Termo utilizado por Vigotski (1997) no Tomo V das Obras Completas, atualizado à medida que se ampliam as discussões, sendo que atualmente a denominação "pessoa com deficiência” é entendida como a mais coerente.

\section{REFERÊNCIAS}

BARROCO, Sonia Mari Shima. A educação especial do novo homem soviético e a psicologia de L. S. Vigotski: implicaçóes e contribuiçóes para a psicologia e a educação atuais. 2007. 414 f. Tese (Doutorado em Educação Escolar) - Universidade Estadual Paulista, Araraquara, SP, 2007.

BRASIL. Ministério da Educação. Secretaria de Educação Especial. Atendimento Educacional Especializado: Deficiência Mental. Brasília, DF:MEC/SEESP, 2007.

BRASIL. Ministério da Educação. Atendimento Educacional Especializado: aspectos legais e orientaçóes pedagógicas. Brasília, DF: MEC/SEESP, 2007c.

BRASIL. Política Nacional de Educação Especial na Perspectiva da Educação Inclusiva. Brasília, DF: MEC/SEESP, jan. 2008.

BRASIL. Ministério da Educação. Conselho Nacional de Educação. Câmara de Educação Básica. Resolução no 4, de 2 de outubro de 2009.Institui Diretrizes Operacionais para o Atendimento Educacional Especializado na Educação Básica, modalidade Educação Especial. Diário Oficial da União, Brasília, DF, 5 out. 2009.

BRASIL. Ministério da Educação. O Atendimento Educacional Especializado para alunos com Deficiência Intelectual. Brasília, DF: SEESP/MEC, 2010. (Coleção A Educação Especial na Perspectiva da Inclusão Escolar, v. 2). 
CARVALHO, Alfredo Roberto de. Inclusão social e as pessoas com deficiência: uma análise na perspectiva crítica. 2009.178 f. Dissertação (Mestrado em Educação) Universidade Estadual do Oeste do Paraná, Cascavel, PR, 2009.

DELORS, Jacques (Org.). Educação: um tesouro a descobrir. São Paulo: Cortez, 1998.

DERISSO, José Luis. Construtivismo, pós-modernidade e decadência ideológica. In: MARTINS, Lígia Márcia; DUARTE, Newton (Org.). Formação de professores: limites contemporâneos e alternativas necessárias. São Paulo: Editora da UNESP; Cultura Acadêmica, 2010. P. 51-61. Disponível em: <http://static.scielo.org/scielobooks/ysnm8/pdf/martins-9788579831034.pdf>. Acesso em: 20 dez. 2013.

DUARTE, Newton. Concepçóes afirmativas e negativas sobre o ato de ensinar. Cadernos CEDES, Campinas, SP, v. 19, n. 44, p. 85-106, 1998.

DUARTE, Newton. O Construtivismo seria Pós-Moderno ou o Pós-Modernismo seria Construtivista? In: DUARTE, Newton (Org.). Sobre o Construtivismo: contribuições a uma análise crítica. 2. ed. Campinas, SP: Autores Associados, p. 87-106, 2005.

DUARTE, Newton. Vigotski e o "aprender a aprender": crítica às apropriaçôes neoliberais e pós-modernas da teoria vigotskiana. 4. ed. Campinas, SP: Autores Associados, 2006.

FACCI, Marilda. Gonçalves Dias. Formação de Professores: valorização ou esvaziamento do trabalho do professor? Um estudo da teoria do professor reflexivo, do construtivismo e da psicologia vigotskiana. São Paulo: Autores Associados, 2004. LEONTIEV, Alexei Nikolaevich. O desenvolvimento do psiquismo. Lisboa: Livros Horizonte, 1978.

LURIA, Alexander Romanovich. Desenvolvimento cognitivo: seus fundamentos culturais e sociais. São Paulo: Ícone, 2008.

MARTINS, Lígia Marcia. Implicações pedagógicas da escola de Vigotski: algumas consideraçôes. In: MENDONÇA, Sueli Guadelupe de Lima; MILLER, Stela. Vigotski e a escola atual: fundamentos teóricos e implicaçôes pedagógicas. 2. ed. Marília, SP: Cultura Acadêmica, p. 49-61, 2010.

MARX, Karl; ENGELS, Friedrich. Manifesto do Partido Comunista. São Paulo: Cortez, 1998. 
PADILHA, Anna Maria Lunardi. Práticas Pedagógicas na Educação Especial: a capacidade de significar o mundo e a inserção cultural do deficiente mental. 2.ed. Campinas, SP: Autores Associados, 2005.

PERTILE, Eliane Brunetto. A Sala de Recursos Multifuncional: a proposta oficial para o trabalho docente frente às necessidades dos alunos com deficiência intelectual. 165f. Dissertação (Mestrado em Educação), Cascavel, PR: UNIOESTE, 2013. ROSSETTO, Elisabeth. Sujeitos com deficiência no Ensino Superior: vozes e significados. 2009. 238 f. Tese (Doutorado em Educação) - Universidade Federal do Rio Grande do Sul, Porto Alegre, 2009.

ROSSETTO, Elisabeth. Os sujeitos da educação especial a partir da perspectiva Histórico-Cultural. In: ROSSETTO, Elisabeth; REAL, D. C (Org.). Diferentes modos de narrar os sujeitos da educação especial a partir de.... Cascavel, PR: EDUNIOESTE, p. 55-72, 2012.

SAVIANI, Demerval. A nova lei da educação: trajetória, limites e perspectivas. Campinas, SP: Autores Associados, 1997.

SAVIANI, Demerval. Escola e democracia: teorias da educação, a curvatura da vara, onze teses sobre educação política. 36. ed. revista. Campinas, SP: Autores Associados, 2003.

SFORNI, Marta Sueli de Faria. Aprendizagem e desenvolvimento: o papel da mediação.

In: CAPELLINI, Vera Lúcia F.; MANZONI, Rosa Maria (Org.). Políticas públicas, práticas pedagógicas e ensino-aprendizagem: diferentes olhares sobre o processo educacional. São Paulo: Cultura Acadêmica, 2008. Disponível em: <http://www.diaadia.pr.gov.br/nre/ibaiti/ arquivos/File/Sforni.pdf>. Acesso: $22 \mathrm{dez}$. 2011.

SHIROMA, Eneida Oto; CAMPOS, Roselane Fátima; GARCIA, Rosalba Maria Cardoso. Decifrar textos para compreender a política: subsídios teóricometodológicos para análise de documentos. Perspectiva, Florianópolis, SC, v. 23, n. 2, p. 427-446, jul./dez. 2005.

SOUZA, Maria Cecília Braz Ribeiro de. A concepção de criança para o enfoque Histórico-Cultural. 2007. 165 f. Tese (Doutorado em Educação) - Universidade Estadual Paulista, Marília, SP, 2007. 
VIGOTSKI, Lev Semenovich. Fundamentos de Defectología. Cuba: Pueblo Educación, 1983. (Obras completas, v. 5).

VIGOTSKI, Lev Semenovich. Obras escogidas: fundamentos de defectología. Madrid: Visor, 1997.v. 5.

VYGOTSKY, Lev Semenovich; LURIA, Alexander Romanovich. Estudos sobre a história do comportamento: o macaco, homem primitivo e criança. Porto Alegre: Artes Médicas, 1996. 


\section{Multifunction Resource Room for students with intellectual disabilities: an analysis of the Ministry of Education proposal}

\section{Abstract}

The article exposes the result of a documentary and bibliographic research that aimed to investigate the Ministry of Education proposal (MEC) directed to students with intellectual disabilities in the Multifunctional Resource Room (SRM). Thus, legal normative proposed by the Brazilian Ministry of Education and Culture (MEC) that support and guide rightfully the action of these professors have been prioritized. In the light of Historic-Cultural Theory, the concept of human development, of learning and teaching mediation (education) underlying the guidelines announced by MEC, are analyzed. It is also highlighted the importance attached (or not) to the school content. At the end of this research we can say that the guidelines published by MEC advocate a spontaneous education whose characteristics are antagonistic to the assumptions of the HistoricCultural Theory and we can also say that the organization of a educational action covering the necessities of the students requires a counter proposal that values teaching mediation and the ownership of content. It is noticed that the preparation directed towards teachers is imbued with characteristics that denote emphasis on technical procedures and the use of available resources. So, it is understood that the organization of an educational action boosts students' intelectual development demands a counter proposal that gives value to the the teaching mediation and appropriation of content.

Keywords: Multifunctional Resource Room. Students With Intellectual Disabilities. Teacher Training.
Sala de Recursos Multifuncional para alumnos con discapacidad intelectual: un análisis de la propuesta del Ministerio de Educación

\section{Resumen}

El artículo expone el resultado de una búsqueda documental y bibliográfica que tuvo como objetivo investigar la propuesta del Ministerio de Educación (MEC) para llevar a cabo las actividades de enseñanza con los alumnos con discapacidad intelectual en las Clases de Recursos Multifuncionales (SRM). Por lo tanto, damos prioridad a las publicaciones editadas por el MEC para guiar la acción de estos profesores. Se analiza a la luz de la Teoría Histórico-Cultural el concepto de desarrollo humano, el aprendizaje y de la mediación (enseñanza) que subyace a las directrices anunciadas; Destacamos también la importancia (o no) a los contenidos escolares. Al final de esta investigación se puede afirmar que las directrices publicadas por el MEC defienden una perspectiva de educación que le otorga demasiada importancia a la espontaneidad. Así, tiene características antagónicas a los presupuestos de la Teoría Histórico-Cultural. También constatamos que la preparación dirigida a los profesores está impregnada de características que denotan énfasis en los procedimientos técnicos y el uso de los recursos disponibles. Entendemos que la organización de una acción educativa que traería el desarrollo intelectual de los estudiantes requiere una propuesta distinta, que valora la mediación enseñanza y la apropiación de los contenidos.

Palabras claves: Sala de Recursos Multifuncional. Alumnos con Discapacidad Intelectual. Formación Docente. 


\section{Eliane Brunetto Pertile}

E-mail: elianebrunetto@gmail.com

\section{Elisabeth Rossetto}

E-mail: erossetto2013@gmail.com

Recebido em: 21/03/2014

Aprovado em: 12/03/2015 
